\title{
MIDWIVES COPING WITH STRESS
}

\author{
Slavena Ilieva, Valya Dimitrova, Rumyana Laleva \\ Department of Health Care, Faculty of Public Health, Medical University of Varna
}

\begin{abstract}
Professional stress can be defined as an emotional, cognitive, behavioural and psychological reaction to negative and unfavourable aspects related to the nature of the work. This reaction affects the whole organism and its environment, can become a permanent condition and is characterised by a high degree of suffering, and often with a sense of impasse. According to NIOSH (National Institute for Occupational Safety and Health), occupational stress is a combination of negative physical and emotional responses that occur when there is a mismatch between job requirements and capabilities, resources or needs of the worker.
\end{abstract}

AIM: The aim of this study is to determine the ability of midwives working in the St. Anna University Hospital and SHOGAT "Prof. Dr. D. Stamatov“, Varna, to cope with stress arising from the job environment.

MATERIALS AND METHODS: We have studied the opinion of working midwives from St. Anna University Hospital and SHOGAT „Prof. Dr. D. Stamatov“ - Varna. The survey was conducted in June 2016. The methods we used were: documentary, statistical - questionnaire, graphic analysis.

RESULTS AND DISCUSSION: The answer of the respondents indicates an increased workload, which can be a source of stress. Increased physical overload and emotional exhaustion in the workplace are a prerequisite for the emergence of stress. The accumulated fatigue and inadequate rest decrease the ability to work and are a prerequisite for the occurrence of stress among working midwives. Many midwives work a second job or have family (other) obligations that prevent them from getting adequate rest. It is noteworthy to mention that more than half of the midwives choose their relatives and friends to share the emotions experienced during the day.

\section{CONCLUSIONS:}

1. Increased physical overload and emotional exhaustion in the workplace are a prerequisite for the emergence of stress.

2. The accumulated fatigue and inadequate rest decrease the ability to work and are a prerequisite for the occurrence of stress among working midwives.

3. Stress is the cause of discomfort among midwives.

4. Respondents choose to share with family and friends to overcome stress.

Keywords: professional stress, midwives, workplace

Address for correspondence:

Slavena Ilieva

Faculty of Public Health

Medical University of Varna

55 M. Drinov St.

e-mail: slavena8837@abv.bg 
Slavena Ilieva, Valya Dimitrova, Rumyana Laleva

\section{INTRODUCTION}

According to NIOSH (National Institute for Occupational Safety and Health) occupational stress is a combination of negative physical and emotional responses that occur when there is a mismatch between job requirements and capabilities, resources or needs of the worker. This stress can cause health problems and even accidents. Stress occurs when such situations occur too often with high intensity and duration.

Professional stress can be defined as emotional, cognitive, behavioural and psychological reaction to negative and unfavourable aspects related to the nature of the work. This reaction affects the whole organism and its environment, can become a permanent condition and is characterised by a high degree of suffering, and often with a sense of impasse.

Kaiser and Hansen considered occupational stress as the response of the employees to the requirements of the labour situation. The employees doubt they have the necessary resources to implement these requirements but they are nevertheless obliged to perform them.

\section{RESULTS AND DISCUSSION}

People spend most of their everyday life in the workplace and it is normal to want to feel good there. Everyday life and dynamic lifestyles lead to a significant increase of stress levels.

It was interesting for us to study the opinion of midwives on the physical and mental load at the work place. We asked them if they thought the work they did was hard (Fig. 1).

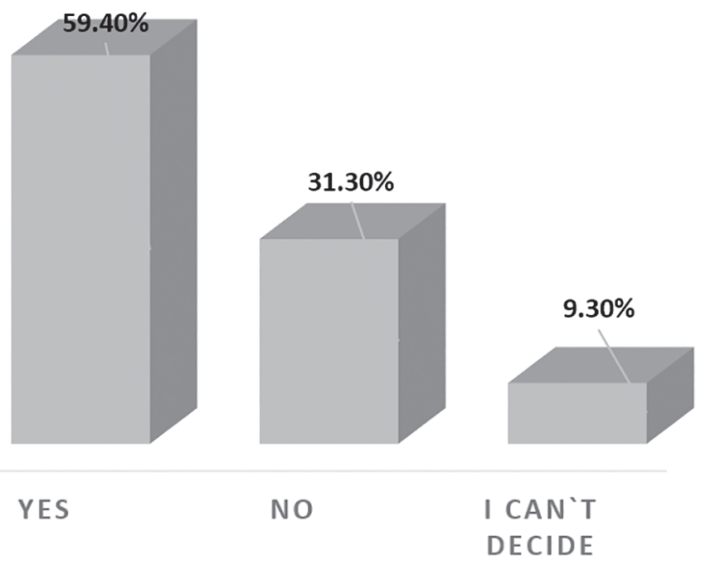

Fig. 1. Load at work place
The answer of the respondents testifies to the increased load of work, which can be a source of stress. The hesitation of some of the respondents may be explained by insufficient knowledge and skills to recognise and cope with occupational stress.

Physical overstrain at work for midwives may also be a reason for the occurrence of emotional exhaustion. It can result in lower quality of care, psychosomatic health problems and even denial to exercise the profession. We asked midwives whether they felt emotionally exhausted at the end of the working day (Fig. 2).

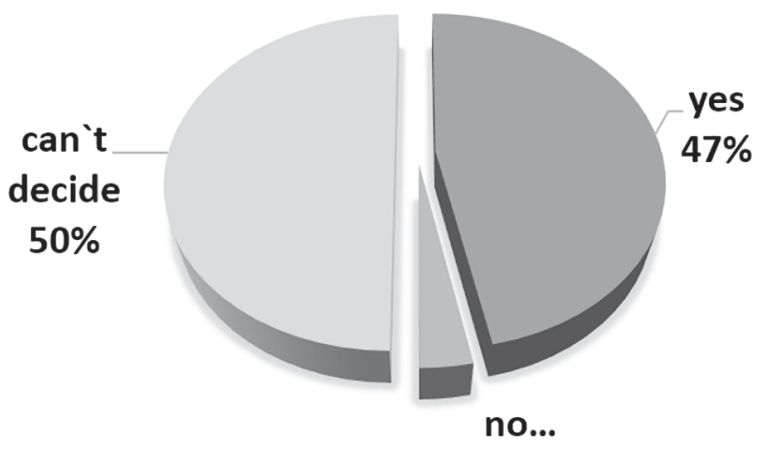

Fig. 2. Emotional stress

Nearly half of the respondents say they feel emotionally exhausted at the end of duty (47\%), and the rest note that this happens sometimes (50\%). For a fraction of the respondents the end of the working day is not associated with emotional exhaustion (3\%). The answers of the respondents are evidence that mental overload in the workplace is a major problem for practising midwives, which requires the implementation of measures to prevent and deal with it. Data analysis shows that midwives are aware of the emotional stress and it is significant, which requires the implementation of organisational measures to reduce its levels.

Physical fatigue and emotional stress in the workplace require taking a number of measures to overcome them, such as - enough sleep, walking, hobbies, entertainment and so on. We were interested in how midwives recover after 12 hours of duty (Fig. 3).

It is noteworthy to mention that more than half of the respondents indicate that they do not relax after work, doing other tasks (53.2 percent). About 1/3 


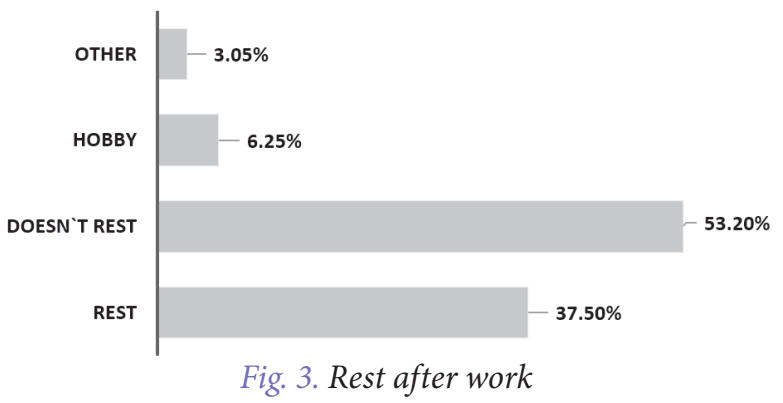

of the respondents after a long day indulge in a deserved rest (37.5\%), suggesting that they can afford it. A very small part of the midwives indulge in their hobbies or other pursuits $(6.25 \%$ and $3.05 \%$, respectively). When one is overworked, he (she) is incomplete. The accumulated over time fatigue, and the lack of time for adequate rest reduce work capacity, and are a prerequisite for the occurrence of stress among working midwives.

After analysing the results, it should be noted that for the majority of respondents the fatigue from work is great, which may be due to the lack of sufficient time to recover and rest.

Relaxing after work is beneficial, and helps to cope with stress more quickly. This is not likely to happen, as many midwives work a second job or have family (other) obligations that prevent them. The data analysis shows that more than half of the respondents work on a second employment contract permanently (37\%) or occasionally (16\%). If we venture to comment on the results as a whole, it appears that more than half of the midwives are forced to work two jobs, which overstrains them physically and mentally (53\%). We can assume that the main reason for this is dissatisfaction with the payment. Less than $1 / 2$ of the respondents indicated that they did not have to work a second employment contract. From here we can assume that excessive physical exertion is related to the lack of time for complete relaxing (Fig. 4).

Everyone has a personality that determines one's reaction in a given situation. We were interested in the feelings, experienced by midwives under stress, and we got the following results (Fig. 5).

The largest share is that of respondents who experience general fatigue and insomnia (38\%), and anxiety and stress (39\%). About 1/5 of the respondents reported headaches and palpitations, $15 \%$ and

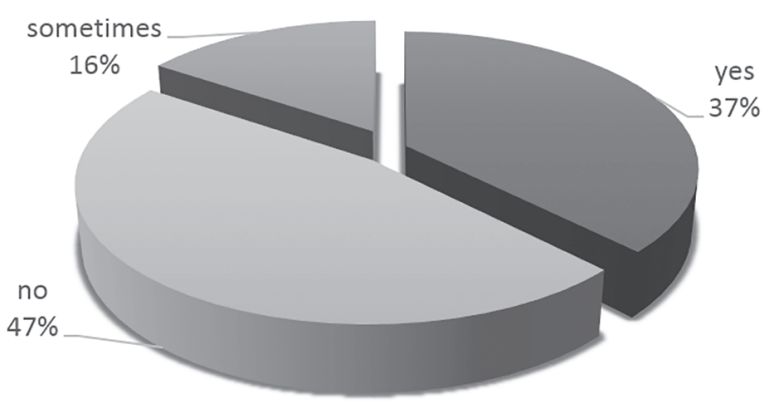

ayes no $\quad$ sometimes

Fig. 4. Second job

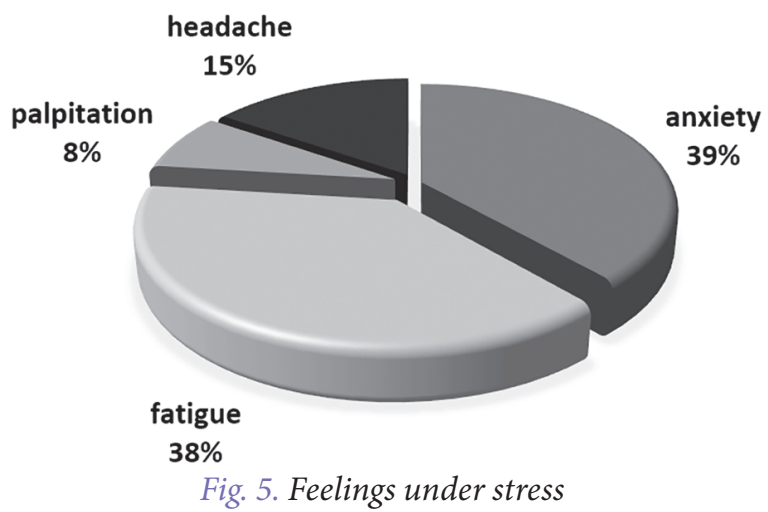

$8 \%$ respectively. Stress is the cause of ailments among midwives, inevitably leading to reduced working capacity, difficulties in organisation and execution of daily work tasks.

We were interested in understanding how midwives cope with stress arising from the professional environment (Fig. 6).

It is noteworthy to indicate that more than half of the midwives choose their relatives and friends to share the emotions experienced during the day

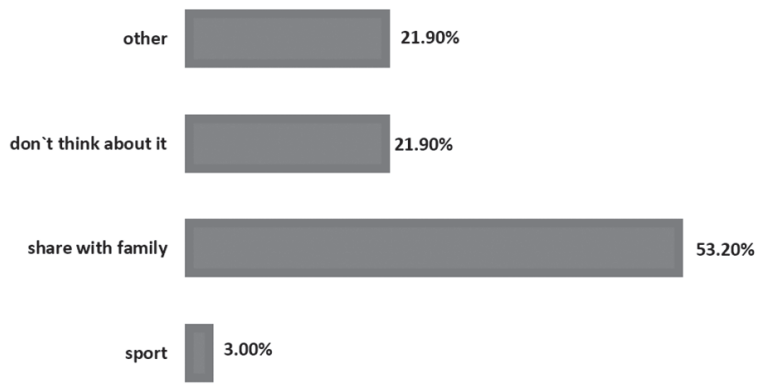

Fig. 6. Coping with stress 
(53.2\%). About $1 / 5$ of the respondents prefer not to think about the source of stress (21.9\%). Perhaps the reason for the respondents to share with their loved ones is their strong emotional support, offered at a difficult time. Others prefer not to share, which may lead to mental strain and internal conflict. Midwives who prefer not to think about what happened probably do not want to burden their relatives and acquaintances and avoid sharing with them negative experiences of professional nature.

Physical activity has proven to be a very good alternative for dealing with stress. A negligible share of respondents resorted to sport as a means of overcoming stress (3\%), which is probably also due to the lack of free time.

We asked the midwives if they needed additional information on stress and coping techniques. Almost $1 / 2$ of the respondents indicate that they need this information, and about $1 / 10$ are undecided ( $41 \%$ and $12 \%$, respectively).

\section{CONCLUSIONS}

1. Increased physical overload and emotional exhaustion at the workplace are a prerequisite for the emergence of stress.

2. The accumulated fatigue and inadequate rest decrease the ability to work and are a prerequisite for the occurrence of stress among working midwives.

3. Stress is the cause of discomfort among midwives.

4. Respondents choose to share with family and friends in order to overcome stress.

\section{REFERENCES}

1. Atanasova I. Relatioship between stress and satisfaction at work place. Sestrinsko delo. 2012; 1: 16-21.

2. Muhina S. Theoretical foundation of sisterhood. MU-Pleven; 2006.

3. Popov H. Posttraumatic stress. Lik; 2003.

4. Stambolova I, Dimitrova M, Bikova P. How nurses rest. Zdravni griji.

5. http://www.knsb-bg.org/pdf/report-final-ilo-b.pdf

6. http://www.loramed.com/Kak-da-se-spravim-sysstresa-na-rabotnoto-masto-p234.html
7. https://osha.europa.eu/bg/themes/ psychosocial-risks-and-stress

8. http://otgovori.info/faktori/stres/ kakvo-e-profesionalen-stres/ 